\title{
Preventing deaths from rising opioid overdose in the US - the promise of naloxone antidote in community-based naloxone take-home programs
}

This article was published in the following Dove Press journal:

Substance Abuse and Rehabilitation

30 August 2013

Number of times this article has been viewed

\section{Michele M Straus \\ Udi E Ghitza \\ Betty Tai}

Center for the Clinical Trials Network, National Institute on Drug Abuse, National Institutes of Health, United States Department of Health and Human Services, Bethesda, MD, USA
Correspondence: Betty Tai Center for the Clinical Trials Network, National Institute on Drug Abuse, National Institutes of Health, 600 I Executive Boulevard, Bethesda, MD 20892, USA

$\mathrm{Tel}+\mathrm{I} 30$ I 4438888

Fax +I 30I 4432317

Email btai@nida.nih.gov
Abstract: The opioid overdose epidemic is an alarming and serious public health problem in the United States (US) that has been escalating for 11 years. The 2011 National Survey on Drug Use and Health (NSDUH) demonstrated that 1 in 20 persons in the US aged 12 or older reported nonmedical use of prescription painkillers in the past year. Prescription drug overdose is now the leading cause of accidental death in the United States - surpassing motor vehicle accidents. Great efforts have been initiated to curb the overdose crisis. Notable examples of these efforts are (1) the Drug Enforcement Administration's (DEA) National Take-Back Initiative instituted in 2010; (2) the Prescription Drug Monitoring Programs (PDMPs) implemented in most US states to provide practitioners with point-of-care information regarding a patient's controlled substance use; (3) the naloxone rescue programs initiated in the community to avert mortality resulting from overdose. The use of naloxone rescue strategies has gained traction as an effective measure to prevent fatal opioid overdose. Many US federal-government agencies are working to make these strategies more accessible to first responders and community participants. This new approach faces many challenges, such as accessibility to naloxone and the equipment and training needed to administer it, but none is more challenging than the fear of legal repercussions. US federal-government agencies, local governments, health care institutions, and communitybased organizations have begun to tackle these barriers, and naloxone take-home programs have gained recognition as a feasible and sensible preventive strategy to avoid a fatal result from opioid overdose. Although many challenges still need to be overcome, it is important for federal government research agencies to initiate and support independent and rigorous evaluation of these programs to inform policymakers how effective these programs can be to save lives and curb the opioid overdose public health crisis.

Keywords: prescription drug abuse, fatal opioid overdose, naloxone antidote, Good Samaritan laws, naloxone take-home program

\section{Introduction}

Prescription drug overdose is now the leading cause of accidental death in the United States (US) - surpassing motor vehicle accidents in 2012. One in six US teens has taken medicines prescribed for someone else, and most have obtained the medicines from a family member or friend who is unaware of the dangers they pose. ${ }^{1}$ In the last two decades, the misuse and abuse of prescription opioids grew at exponential rates partly due to aggressive pain treatment with prescription opioid analgesics. ${ }^{2}$

Opioid analgesic overdose deaths tripled between 1999 and 2008. ${ }^{3}$ The 2010 National Survey on Drug Use and Health (NSDUH) demonstrated that 1 in 20 persons aged 12 or older in the US reported nonmedical use of prescription painkillers in the past year. ${ }^{4}$ The rates of nonmedical use of prescription painkillers remain high in the 
2011 NSDUH report. ${ }^{5}$ US data from the 1999-2008 National Vital Statistics System, the 1999-2010 Automation of Reports and Consolidated Orders System (ARCOS) of the Drug Enforcement Administration (DEA) and the 1999-2009 Treatment Episode Data Set (TEDS) demonstrate a steady and significant increase in the rates of prescription painkiller sales, deaths, and substance abuse treatment admissions during the period from 1999 to 2010 (Figure 1). ${ }^{6}$ As shown in Figure 2, there have been dramatic increases in accidental drug overdose deaths during the past decade. In 2007, there was one accidental drug overdose death every 19 minutes. Specifically, abuse or misuse of opioid analgesics have contributed significantly to the increase in drug-related overdose deaths in the past decade. ${ }^{7}$ The numbers of opioid analgesicrelated overdose deaths have exceeded that of cocaine and heroin combined (Figure 3$)^{7}$

The fundamental approach to the prevention of such a rise in tragic deaths is to expand the medical capacity to offer preventive care to high-risk drug users and to increase access to and use of comprehensive treatment for addicted patients. Very recently, the US has implemented additional ancillary programs to further curb the overdose crisis by reducing and monitoring the supply of the drugs frequently implicated in overdose. One such program available in the community is the Drug Enforcement Administration's (DEA) National Take-Back Initiative instituted in 2010. A series of National Take-Back Events have been conducted to collect unused medications in order to reduce the volume of prescription drugs available in the community. This program identifies law enforcement and health care partners who are designated to receive unwanted medications from community members, and arrange for their proper destruction. During the 2012
Take-Back Events alone, an estimated 520 tons of unwanted or expired medications were collected. ${ }^{8,9}$

Another program designed to reduce the volume of prescription drugs available for illicit or nonmedical use is the Prescription Drug Monitoring Program (PDMP) implemented in many states across the US. PDMPs can offer a means of monitoring patient adherence to appropriate opioid therapy, detecting patient misuse or diversion of opioids and enabling practitioners to have point-of-care information regarding a patient's controlled substance use.

Recent findings point to an alarmingly low rate of primary care physicians' utilization of appropriate clinical strategies to reduce risk of opioid misuse in patients with chronic pain who have been prescribed opioid analgesics. ${ }^{10}$ These data suggest that many primary care physicians do not employ preventive strategies for reducing substance abuse in chronic pain patients who are considered to be at high risk for opioid misuse. These data underscore the urgent public health need to implement PDMPs and to train and encourage practitioners to utilize these programs together with established clinical practice guidelines and evidence-based clinical decision support tools to properly monitor opioid therapy. Practical benefits of PDMPs have been described, including how their use improves the quality of medical practice in general medical settings and enhances detection of opioid misuse and clinical responses to likely 'doctor shopping'. ${ }^{11}$

In addition to these measures to reduce supply, there is a pharmacological approach that can directly and immediately reverse opioid overdose if administered properly, ie, naloxone. Naloxone is an opioid mu-receptor antagonist and can effectively reverse overdose and its deadly consequences. However, there are multiple barriers to overcome before

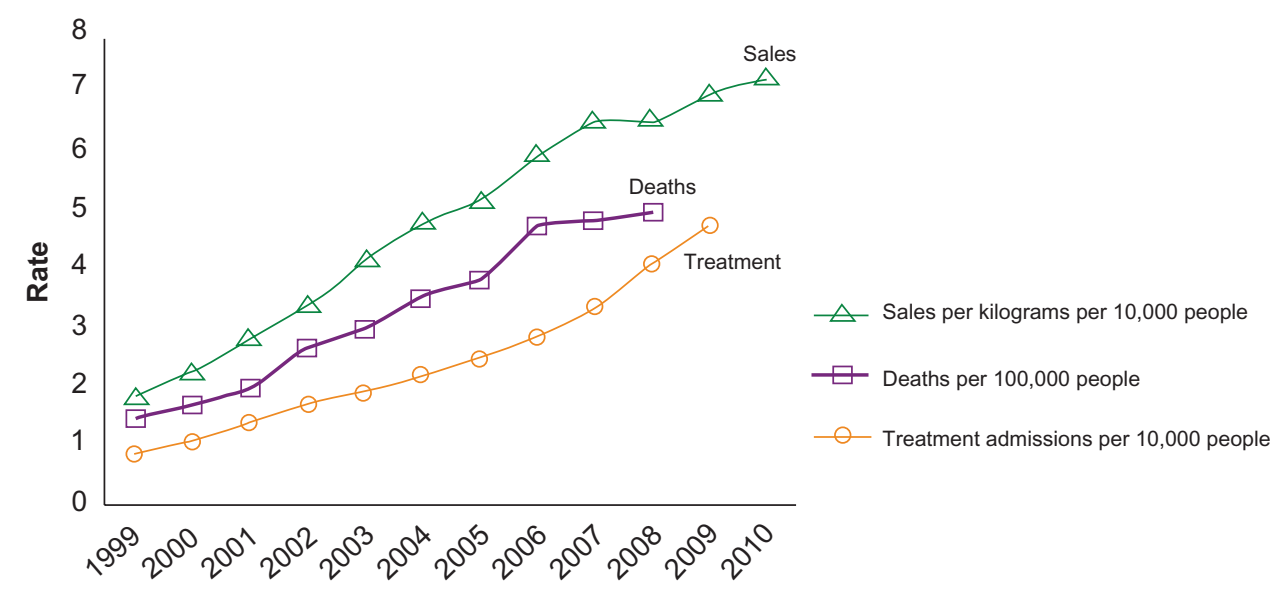

Figure I Rates of prescription painkiller sales, deaths, and substance abuse treatment admissions (1999-20I0).

Notes: Data obtained from Centers for Disease Control and Prevention (CDC). Vital signs: overdoses of prescription opioid pain relievers - United States, $1999-2008$. MMWR Morb Mortal Wkly Rep. 201 I;60(43): I487-1492. ${ }^{6}$ 


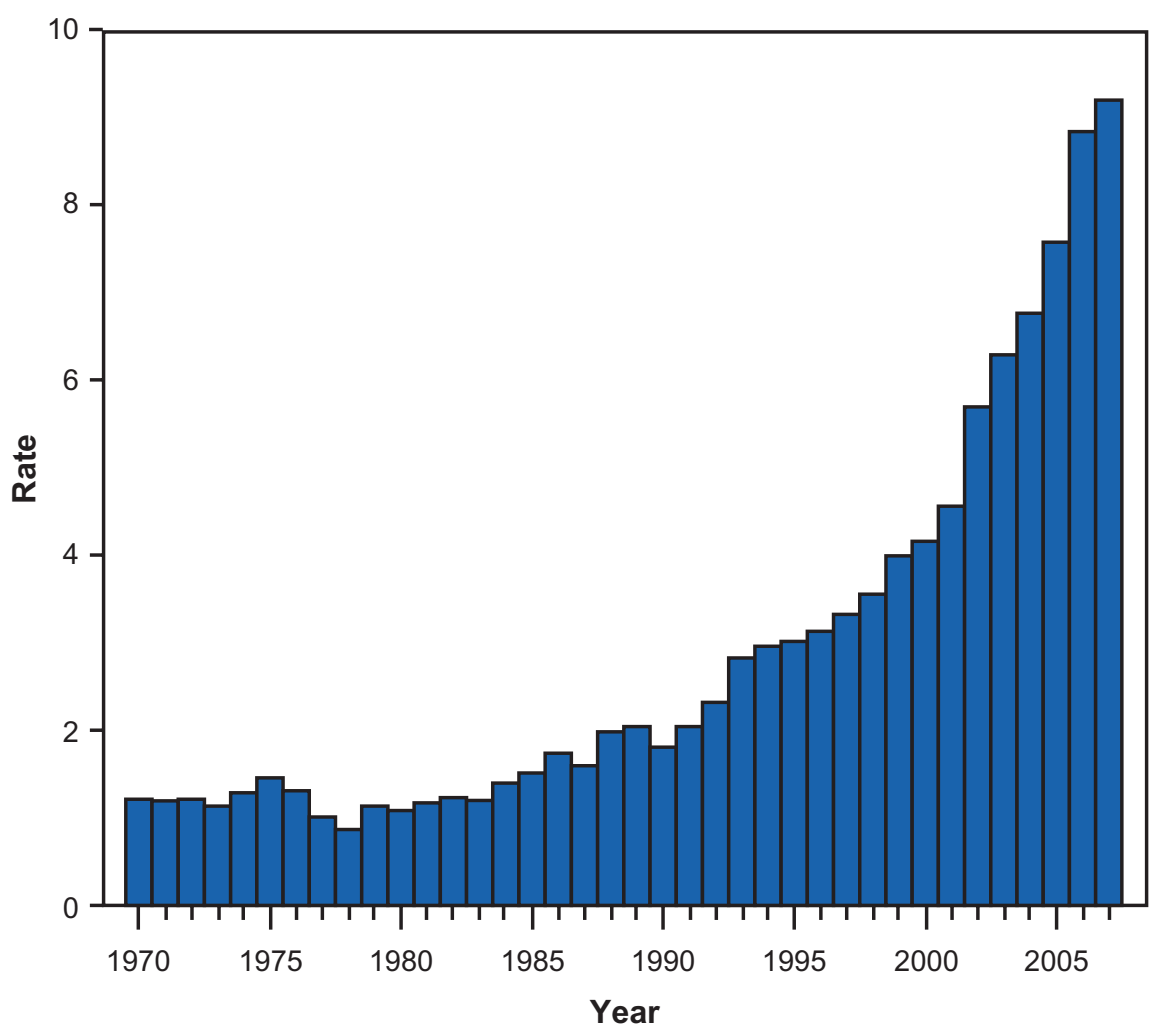

Figure 2 Rate* of unintentional drug overdose deaths - United States 1970-2007.

Note: *Per 100,000 population. Data obtained from Centers for Disease Control and Prevention (CDC). CDC grand rounds: prescription drug overdoses - a US epidemic. MMWR Morb Mortal Wkly Rep. 2012;6I (I):10-13.7

its use outside the medical setting can be widely adopted. This paper will provide an overview of the challenges and opportunities encountered by efforts in community naloxone programs to distribute naloxone and train in its use to reverse opioid overdose and prevent death.

\section{Naloxone antidote to reverse opioid overdose}

For many years in the US, public perception, health policy, and law have influenced treatment goals in substance use

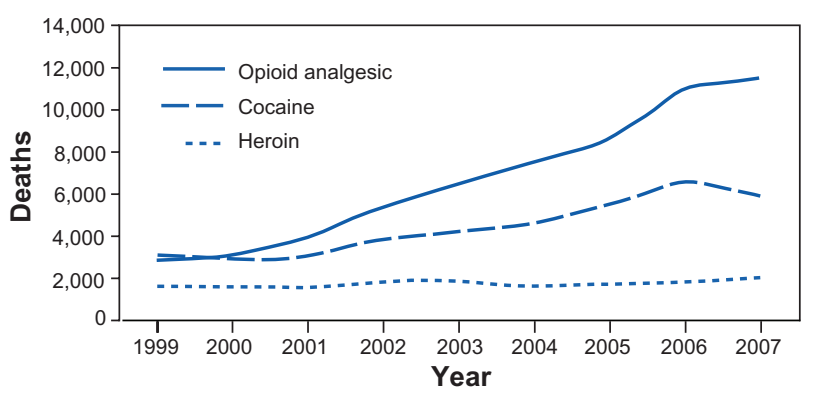

Figure 3 Number of unintentional drug overdose deaths involving opioid analgesics, cocaine, and heroin - United States, 1999-2007.

Notes: Data obtained from Centers for Disease Control and Prevention (CDC). CDC grand rounds: prescription drug overdoses - a US epidemic. MMWR Morb Mortal Wkly Rep. 2012;61 (I): 10-13.7 disorders, resulting in the development of abstinence as the expected outcome for treating patients with illicit drug use problems. However, reduction in substance use has not been the goal of most treatment programs, as it was not an acceptable outcome on several fronts. ${ }^{12}$ Increased awareness of the medical sequelae of the misuse and abuse of illicit and prescription drugs has resulted in a reassessment of abstinence as the only goal of treatment. As an example, medical consequences of the abuse of opioids, such as an alarming increase in fatal overdoses resulting from severe respiratory suppression and other adverse opioid effects, have provided the impetus for immediate change in approach to emergency handling of drug-related overdose in community settings.

Recently, a new approach has been initiated by policymakers to respond to this public health threat. ${ }^{13}$ This approach allows for a broad range of treatment and research goals in substance use disorders, including introducing non-abstinence-directed initiatives into publicly funded treatment and research. In recent years, the US National Drug Control Strategy has reflected this new course of action, and thus, directly addresses the epidemic in opioid overdose by opening a discussion for the use of naloxone by first responders and community participants alike. This approach 
paves the way for other agencies and policymakers to address this need in a cogent and collaborative manner. ${ }^{14}$ As these discussions move forward on several fronts, it is important to understand the nature of the underlying disease, the pharmacology of opioids, and the challenges that will be faced by all involved in efforts to reduce the epidemic proportions of morbidity and mortality associated with drug overdose.

\section{Naloxone as an antagonist}

The function of opioids resembles that of endogenous chemicals that have binding sites in the brain and the body called opioid receptors. There are three types of opioid receptors: $\mathrm{mu}$, delta, and kappa. Each of these receptors mediates different functions. For example, mu-receptors are responsible for the pleasurable effects of opioids, their pain-relieving properties, and the respiratory depression that makes opioid overdose so dangerous. These receptors exist in various places in the brain and nervous system: the limbic system, which controls emotions such as feelings of pleasure, relaxation, and contentment; the brainstem, which controls autonomous nervous system function, like breathing, and coughing, etc; and the spinal cord, which transmits sensations from the body, eg, the feelings of pain, even following serious injuries. ${ }^{15,16}$

Heroin and morphine are mu-opioid-receptor agonists. When they bind to the mu-receptor, they activate the receptor and elicit biological effects, such as pain relief and/or euphoria, suppression of respiration, and constriction of the pupils. On the contrary, naloxone is an opioid antagonist that has higher affinity for the mu-receptor than the delta- and kappa-receptors. It 'competes' with heroin and morphine to bind the mu-receptors. Because naloxone has a higher affinity for these receptors than heroin and morphine, naloxone will generally win out, replacing much of the heroin and morphine at the receptor sites. When naloxone binds to the mu-receptor, it does not elicit the response that an agonist activates, and it prevents the binding of an agonist that will activate the receptor response (Figure 4). Thus, naloxone is an effective antidote for opioid overdose based on its pharmacological properties. Once it is administered, it promptly replaces the agonist and reverses the biological effects that are caused by heroin and/or morphine, reversing the respiratory suppression caused by opioids and consequently reversing fatal opioid overdose. Naloxone has very short serum half-life (30-81 minutes) due to its extensive 'first pass' metabolism. Therefore, as opposed to naltrexone, naloxone cannot be administered effectively orally, and should be administered by injection. Once administered, naloxone is rapidly distributed throughout the body. In the presence of

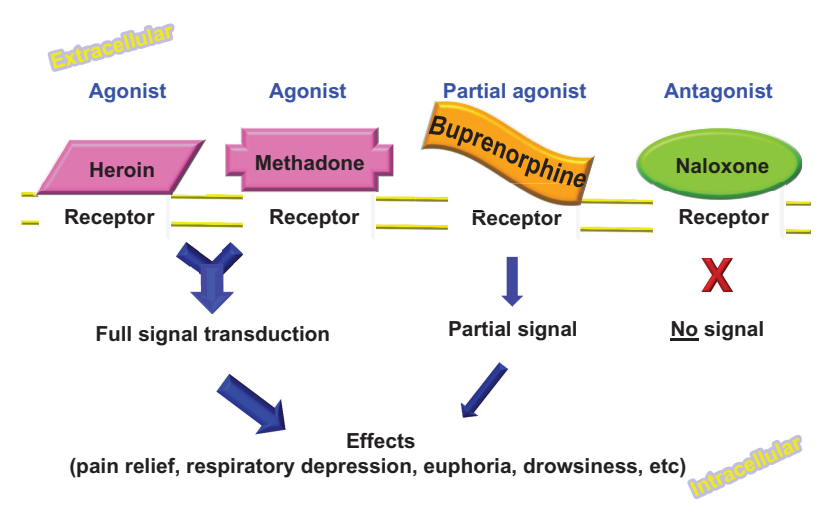

Figure 4 Mu Receptor Pharmacology.

opioid dependence, naloxone may precipitate withdrawal symptoms. In the clinical setting, within 1-3 minutes of a sufficient naloxone injection (0.4-2 $\mathrm{mg}$ ), a patient who has overdosed on morphine will generally wake up, usually quite agitated. For the purpose of emergency reversal of a potentially fatal opioid overdose outside of a medical facility, repeated administration is not intended, as the aim of the acute naloxone administration is to reverse the immediate effects of the agonist opioid overdose. Due to the short serum half-life, high affinity of naloxone to the mu-receptor, and the acute consequences of displacing mu agonists from the receptors, it is important that the patient continues to be monitored, and receives ongoing medical attention. Naloxone has no abuse liability or potential for misuse..$^{17,18}$

\section{Opportunities and challenges of using naloxone as an antidote for opioid overdose}

The strategy of providing naloxone directly to drug users to reverse opioid overdose was originally adopted in 1996 at a take-home naloxone project in Chicago. ${ }^{19}$ As of 2010, there were 48 known programs, representing 188 communitybased sites in 15 states and the District of Columbia. Of note, there were an estimated 10,171 overdose reversals reported from 1996 to June $2010 .{ }^{19}$ In addition, the naloxone distributed was mainly parenteral naloxone (delivered by intramuscular injection), with less than $10 \%$ of programs providing intranasal naloxone. Both public-funded and private non-profit programs have been involved in this take-home naloxone project. For general medical use, naloxone requires a prescription and is generally ordered by a prescriber and distributed by a pharmacy.

One of the most notable programs is the DOPE Project, funded by the San Francisco (SF) Department of Public Health. 
Initiated as a grassroots effort in 1993, in May 2010, DOPE began distributing intranasal naloxone in accordance with standing medical orders at all SF needle exchange programs and sites, methadone maintenance programs, and other community-based programs. Results were presented in a webinar series from the Network for Public Health Law that assessed the SF Medical Examiner's reports. These reports showed a significant and continuous trend in the reduction of opioid overdose deaths from a high in $1996 .^{20,21}$

Despite the sound pharmacological rationale and evidence of positive outcome using naloxone as an effective antidote for fatal opioid overdose, the wide adoption of this approach is still very limited. Reasons are at least two-fold: the lack of wide access to naloxone and the fear of civil liability and criminal prosecution by prescribers, bystanders, and first responders who would administer naloxone to overdosed drug users.

\section{Lack of access and lack of training}

Reports suggest that there is a severe shortage of naloxone, which contributes to its low accessibility. ${ }^{13,22}$ Although naloxone is not a controlled substance, it does require a prescription by a licensed provider, limiting access to naloxone by non-prescribers. Obstacles to obtaining a naloxone prescription include a lack of motivation to prescribe naloxone because clinicians do not regularly screen patients for risk of opioid overdose and therefore do not offer naloxone or overdose education and training for high-risk drug users. The currently available formulation of naloxone is intended to be an injection, which is difficult for lay persons who witness opioid overdose by drug users to administer. Then there is an important concern of civil liability for prescribers and clinicians, especially when naloxone is used outside medical care settings. Unfortunately, these factors can substantially limit the accessibility of naloxone and prohibit the wide adoption of this approach both in extended medical settings and in community-based programs. ${ }^{23}$

\section{Fear of criminal sanctions}

Another major barrier to wide adoption of naloxone in community-based programs is the fear of criminal sanctions. Data suggest that many bystanders and witnesses of overdose episodes are reluctant to administer naloxone or call 911 for emergency rescue because of concerns of arrest or prosecution for either unauthorized practice of medicine and possession of a prescription drug (naloxone), or the fear of being arrested for drug possession, outstanding warrants, or other reasons such as a general fear of police and police practices. ${ }^{24}$

\section{Possible solutions for the lack of access and training}

To address the naloxone supply challenge, a recent Food and Drug Administration (FDA) meeting brought stakeholders from state, local, and federal government agencies together with community providers and patient advocates to discuss potential approaches to increase the availability of and rapid access to naloxone..$^{25}$ At this meeting, various potential solutions to the problem of accessibility were discussed, including changing the legal status of naloxone to overthe-counter or as a co-prescription to opioids, developing alternative delivery methods (eg, an intranasal spray or an auto-injector device), and considering reimbursement for these solutions through the US Centers for Medicare and Medicaid Services (CMS). Another topic discussed was how to enhance education and training by providing evidence-based tool kits and dissemination materials to prescribers, providers, clinicians, drug users, and their families to train them to recognize the signs of overdose and to use effective rescue techniques and emergency supplies of naloxone to reverse the potentially fatal event. Recent results from a survey conducted in 15 states and the District of Columbia (http://www.cdc.gov/mmwr/preview/mmwrhtml/ mm6106a1.htm) showed that approximately a total of 53,032 individuals were trained in naloxone administration and overdose response, and an estimated 10,171 overdose reversals were reported during 1996-2010. Further, many take-home naloxone programs in the US are located at needle exchange programs and the majority of individuals trained are likely to be injection drug users. ${ }^{19}$ These data suggest that non-injection drug users or people who have no access to a needle exchange program may be less likely to participate in a take-home naloxone program.

\section{Possible solutions to address the fear of criminal sanctions}

The fear of criminal penalties may be the biggest challenge for the wide adoption of a naloxone antidote strategy to reverse fatal opioid overdose. This issue is largely addressed at the local level and, dependent on local laws and regulations, many different approaches have been adopted. For instance, these activities conducted in Boston, MA and New York City, NY pose little legal risk for the provider, as they have developed a procedural framework by utilizing state and city health agencies to provide the structure and resources for naloxone distribution coupled with required training about the importance of seeking medical assistance. ${ }^{26}$ The acceptance and utilization of these programs in various geographic locations 
and by those using opioids for non-medical purposes has been considerably enhanced by the tandem passing of state-level legislation known as '911 Overdose Good Samaritan' laws. Many of these laws allow community members to seek or administer aid to overdose victims without suffering legal repercussions regarding their own status of intoxication or possession of illicit substances. These laws vary by state, but they generally are limited in scope to protection from drug possession charges, excluding protection from other drugrelated charges, such as sales and trafficking, or other potential criminal charges. Nonetheless, they do free onlookers, bystanders, and the acquaintances of overdose victims from arrest for the most common offense of possession. Precedents for these laws include similar alcohol-related laws, such as the '911 Lifeline Law' in Texas and policies enacted on many college campuses, as well as 'Baby Moses' and other safe haven laws. ${ }^{27,28}$ The 'New Mexico 911' law was passed in 2007, and the Washington State law was passed in 2010.

Recently, the University of Washington's Alcohol and Drug Abuse Institute published a brief report based on the initial findings from a study funded by the Robert Wood Johnson Foundation Public Health Law Research Program. They surveyed police and users of illicit substances after the law had passed. The findings show that $62 \%$ of police surveyed did not make arrests in these situations prior to the law's passing and would not change this behavior. In addition, $20 \%$ of the surveyed police indicated that they were not sure of their response and 14\% said that the law made it less likely that they would make an arrest. Of the opioid users surveyed, $88 \%$ stated that they would be more likely to call 911 in the event of an overdose after being apprised of the law. ${ }^{24}$ As of May 13, 2013, 11 states and the District of Columbia (NM, WA, NY, CT, IL, CO, RI, FL, MA, NC, CA, and DC) have passed overdose Good Samaritan laws. ${ }^{29}$ Legislation is still pending in Massachusetts, Washington DC, New Jersey, and Hawaii. Several states have similar amnesty laws protecting youths calling 911 for alcohol-related emergencies and federal legislation was also considered: 'HR 2855 (111th) drug overdose reduction' act was referred to committee in the 111th Congress (2009-2010). http://www.govtrack.us/ congress/bills/111/hr2855/text.

In summary, naloxone has sound pharmacological rationale as an effective antidote to reverse fatal opioid overdose. There is accumulated evidence suggesting the feasibility and effectiveness of take-home naloxone projects that provide for the administration of naloxone outside the acute care setting. However, wide adoption of this strategy faces multiple challenges, such as the lack of access to naloxone, training in the proper use of naloxone and follow-up care, and the fear of criminal and civil penalties for those prescribing and administering naloxone. Federal government agencies, community-based treatment providers, and other interested organizations have discussed many potential strategies to increase the accessibility of userfriendly formulations of naloxone and to provide education and training to prescribers, providers, users, onlookers, and family members to identify the warning signs of overdose and the appropriate response, including using naloxone to initiate reversal of this condition. Moreover, state and local governments and community members are working in concert to overcome and minimize the potential criminal sanctions to encourage users and bystanders to call 911 for emergency help when overdose is suspected. It is essential to frame opioid overdose as a treatable medical emergency, and to bring the practice of naloxone administration to reverse potentially fatal opioid overdose into mainstream medical practice.

\section{Conclusion}

The opioid overdose epidemic is an alarming and serious public health problem. The trend has not declined for 11 years. $^{7}$ The use of naloxone as an antidote to reverse fatal opioid overdose has gained traction as an effective preventive measure for fatal opioid overdose. Many US federal government agencies are engaged in dialogue to make this strategy more accessible in the medical setting and in the community. The FDA held a stakeholder meeting on April 12, 2012 to discuss potential approaches to increase the availability of and rapid access to naloxone to prevent fatal opioid overdoses. The potential to distribute naloxone under a new 'over-the-counter-plus' class of drugs and with a more user friendly, improved formulation or delivery device was among the options considered. ${ }^{25}$

Other federal programs could potentially support more comprehensive take-home naloxone programs. Federal funding for research to provide evidence in support of easily administered naloxone formulations and effective approaches to distribute naloxone in the community would aid consideration by regulatory agencies such as the FDA to change the availability of naloxone. This line of research is critical to educate policymakers to provide funding and to change the laws. Training and education could then be funded, to support the dissemination of these findings and advance the use of these lifesaving measures. The practice of using naloxone rescue to combat fatality in overdose could be further advanced by providing reimbursement for overdose 
prevention and specific response education, naloxone prescription and delivery devices, and incentives for providers to adopt these measures more broadly. Public awareness campaigns aimed at wide dissemination of information about risk factors, signs and symptoms, and effective responses to overdose could then be initiated. ${ }^{13}$

Among the many barriers to the full implementation of take-home naloxone programs in community, none is more challenging than the fear of legal repercussions. Emerging evidence suggests that making naloxone more accessible to lay persons, increasing the availability of training tools on the proper administration of naloxone and removal of the threat of potential legal penalties for calling 911 to obtain emergency assistance, can actually save lives. To minimize legal actions, policymakers as well as law enforcement agencies need to partner to deliver the critical message that opioid overdose is a medical emergency and that fatalities are preventable if medical assistance is adequate and timely. The adoption of 'Good Samaritan Laws' and programs allowing community administration of naloxone are the first essential steps as these have demonstrated effectiveness in saving lives. This paper intended to provide an overview of how naloxone can be used as an effective antidote to reverse the overdose of opioids so it does not result in fatality. It explored the many challenges and potential solutions to make this practice widely adopted. US federal government agencies, local governments, health care institutions, and community-based organizations have begun to tackle this epidemic, and naloxone takehome programs have gained recognition as a feasible and sensible preventative strategy to avoid a fatal result from opioid overdose. Although many challenges still need to be overcome, it is important for federal government research agencies to initiate and support independent and rigorous evaluation of these programs to inform policymakers how effective these programs can be to save lives and curb the opioid overdose public health crisis.

\section{Acknowledgments}

Michele Straus, Udi Ghitza, and Betty Tai are employees of the Center for the Clinical Trials Network of the National Institute on Drug Abuse, National Institutes of Health, the funding agency for the National Drug Abuse Treatment Clinical Trials Network. The opinions in this manuscript are those of the authors and do not represent the official position of the US government. The authors gratefully acknowledge the use of Figures 1-3 from the CDC publications cited in the references.

\section{Disclosure}

The authors report no conflicts of interest in this work.

\section{References}

1. Goodlett C. Diverted Rx use by adolescents: treatment research institute takes role in medicine abuse project [press release]. Raleigh, NC: North Carolina Substance Abuse Provider Association and Substance Abuse Federation; September 18, 2012. Available from: http://www. ncsapa.org/2012/diverted-rx-use-by-adolescents-treatment-researchinstitute-takes-role-in-medicine-abuse-project. Accessed November $13,2012$.

2. Lembke A. Why doctors prescribe opioids to known opioid abusers N Engl J Med. 2012;367(17):1580-1581.

3. Hoyert DL, Xu J. Deaths: preliminary data for 2011. Natl Vital Stat Rep. 2012;61(6):1-34.

4. Substance Abuse and Mental Health Services Administration. Results from the 2010 National Survey on Drug Use and Health: Summary of National Findings. Vol NSDUH Series H-41. Rockville, MD: Substance Abuse and Mental Health Services Administration; 2011.

5. Substance Abuse and Mental Health Services Administration. Results from the 2011 National Survey on Drug Use and Health: Summary of National Findings. HHS Publication No (SMA) 12-4713. ed. Rockville, MD: Substance Abuse and Mental Health Services Administration; 2012.

6. Centers for Disease Control and Prevention (CDC). Vital signs: overdoses of prescription opioid pain relievers - United States, 1999-2008. MMWR Morb Mortal Wkly Rep. 2011;60(43):1487-1492.

7. Centers for Disease Control and Prevention (CDC). CDC grand rounds: prescription drug overdoses - a US epidemic. MMWR Morb Mortal Wkly Rep. 2012;61(1):10-13.

8. Justice.gov/DEA. Fourth national prescription drug take-back event collects record 276 tons [press release]. Washington DC: US Department of Justice; May 3, 2012. Available from: http://www.justice.gov/ dea/pubs/pressrel/pr050312.html. Accessed January 7, 2013.

9. Justice.gov/DEA. DEA's fifth national prescription drug take-back day results in another big haul [press release]. Washington DC: US Department of Justice; October 4, 2012. Available from: http://www. justice.gov/dea/docs/results_final.pdf. Accessed October 30, 2012.

10. Starrels JL, Becker WC, Weiner MG, Li X, Heo M, Turner BJ. Low use of opioid risk reduction strategies in primary care even for high risk patients with chronic pain. J Gen Intern Med. 2011;26(9): 958-964.

11. Green TC, Mann MR, Bowman SE, et al. How does use of a prescription monitoring program change medical practice? Pain Med. 2012;13(10):1314-1323.

12. MacMaster SA. Harm Reduction: a new perspective on substance abuse services. Soc Work. 2004;49(3):356-363.

13. Beletsky L, Rich JD, Walley AY. Prevention of fatal opioid overdose. JAMA. 2012;308(18):1863-1864.

14. Whitehouse.gov. National Drug Control Strategy Apr 2012. Available from: http://www.whitehouse.gov/ondcp/2012-national-drug-controlstrategy. Accessed April 8, 2013.

15. Boom M, Niesters M, Sarton E, Aarts L, Smith TW, Dahan A. Non-analgesic effects of opioids: opioid-induced respiratory depression. Curr Pharm Des. 2012;18(37):5994-6004.

16. Ghitza UE. Human brain imaging of opioid receptors: application to CNS biomarker and drug development. In: Seeman P, Madras, B, editors. Imaging of the Human Brain in Health and Disease. Amsterdam, the Netherlands: Elsevier; 2013. Available at: http://neuroscience. com/, http://neuroscience.com/archive/books/book-1-imaging-humanbrain-health-and-disease/human-brain-imaging-opioid-receptorsapplication.

17. Baumann BM, Patterson RA, Parone DA, et al. Use and efficacy of nebulized naloxone in patients with suspected opioid intoxication. Am J Emerg Med. 2013;31(3):585-588. 
18. Naloxone Hydrochloride. AHFS Drug Information. Lexicomp online with AHFS (database). Bethesda, MD: American Socienty of HealthSystem Pharmacists, Inc. Updated April 2, 2013.

19. Wheeler E, Davidson PJ, Stephen Jones T, Irwin KS. Community-based opioid overdose prevention programs providing naloxone - United States, 2010. MMWR Morb Mortal Wkly. 2012;61(6):101-105.

20. The DOPE Project. Oakland, CA: Harm Reduction Coalition; 2012. Available from: http://harmreduction.org/issues/overdose-prevention/ tools-best-practices/naloxone-program-case-studies/dope-project/. Accessed March 6, 2013.

21. Harmreduction.org. Take-Home Naloxone for Opioid Overdose: Exploring the Legal, Policy and Practice Landscapes. Originally posted by the Network for Public Health Law. Oct 2012. Available from: http://harmreduction.org/overdose-prevention/overdose-news/ take-home-naloxone-for-opioid-overdose-exploring-the-legal-policyand-practice-landscapes/. Accessed April 8, 2013.

22. American Society of Health-System Pharmacists. Drug shortages. Report of current availability of naloxone injection. [Mar 2013; updated May 30, 2013]. Available at: http://www.ashp.org/DrugShortages/ Current/bulletin.aspx?id=827. Accessed April 2, 2013.

23. Beletsky L, Ruthazer R, Macalino GE, Rich JD, Tan L, Burris S. Physicians' knowledge of and willingness to prescribe naloxone to reverse accidental opiate overdose: Challenges and opportunities. J Urban Health. 2007;84(1):126-136.
24. Alcohol and Drug Abuse Institute. Washington's 911 Good Samaritan Drug Overdose Law: Initial Evaluation Results. Info Brief University of Washington ADAI. Nov 2011. Available at: http://adai.uw.edu/pubs/ infobriefs/ADAI-IB-2011-05.pdf. Accessed June 18, 2012.

25. US Food and Drug Administration. Role of Naloxone in Opioid Overdose Fatality Prevention; Request for Comments; Public Workshop. Meeting Transcript. Apr 2012. Available at: http://www.fda.gov/ Drugs/NewsEvents/ucm277119.htm?utm_campaign=Google2\&utm_ source $=$ fdaSearch\&utm_medium $=$ website \&utm_term =naloxone\&utm_ content $=3$. Accessed June 4, 2012.

26. Burris S, Norland J, Edlin BR. Legal aspects of providing naloxone to heroin users in the United States. Int J Drug Policy. 2001;12(3): 237-248.

27. Texas Alcohol Beverage Commission. 911 Lifeline Law: Know When to Help. Austin, TX: Texas Alcohol Beverage Commission; 2011. Available at: http://www.tabc.state.tx.us/publications/brochures/ 911-lifeline-policy.pdf. Accessed March 9, 2013.

28. The Baby Moses Project. c1996. Available at: http://www. babymosesproject.org/. Accessed March 9, 2013.

29. Drug Policy Alliance. 911 Good Samaritan Fatal Overdose Prevention Law. New York, NY: Drug Policy Alliance. Available at: http:/www. drugpolicy.org/911-good-samaritan-fatal-overdose-prevention-law. Accessed May 13, 2013.
Substance Abuse and Rehabilitation

\section{Publish your work in this journal}

Substance Abuse and Rehabilitation is an international, peer-reviewed, open access journal publishing original research, case reports, editorials, reviews and commentaries on all areas of addiction and substance abuse and options for treatment and rehabilitation. The manuscript management system is completely online and includes a very quick and fair

\section{Dovepress}

peer-review system. Visit http://www.dovepress.com/testimonials.php to read real quotes from published authors. 